\title{
Effects of follicular cells and FSH on the resumption of meiosis in equine oocytes matured in vitro
}

\author{
J. L. Tremoleda ${ }^{1}$, T. Tharasanit ${ }^{1}$, H. T. A. Van Tol ${ }^{2}$, T. A. E. Stout ${ }^{1}$, \\ B. Colenbrander ${ }^{1,2}$ and M. M. Bevers ${ }^{2 \dagger}$ \\ ${ }^{1}$ Department of Equine Sciences, and ${ }^{2}$ Department of Farm Animal Health, Faculty of \\ Veterinary Medicine, Utrecht University, 3584 CM Utrecht, The Netherlands
}

It has been suggested that preculturing immature oocytes in a manner that maintains them in meiotic arrest may improve cytoplasmic maturation and, thereby, the eventual developmental competence of oocytes matured in vitro. This study examined the ability of follicular cells to maintain meiotic arrest in equine oocytes. Cumulusoocyte complexes (COCs) recovered from dead mares were cultured for $38 \mathrm{~h}$ in M199 either attached to, or together with, different follicle wall components, as follows: (1) attached to the follicle wall, (2) cocultured with separated follicle wall, (3) attached to membrana granulosa (COCG), (4) COCGs cocultured with sheets of theca cells, (5) COCGs cultured in theca-cell conditioned medium, and (6) control COCs without any follicle wall components. When oocytes were cultured attached to their follicle wall, $79 \%$ remained in the GV stage throughout the $38 \mathrm{~h}$ incubation. However, when oocytes were cocultured with separate pieces of follicle wall, meiosis resumed and a similar proportion of oocytes progressed to metaphase II $(79 \%)$ as under control conditions $(84 \%)$. Only $16 \%$ of oocytes cultured while still attached to the membrana granulosa (COCGs) maintained the GV stage, whereas when COCGs were cocultured with theca cells or in theca-cell conditioned medium, significantly more oocytes remained in the GV stage (64 and $52 \%$, respectively), indicating that theca cells secrete a meiosis-inhibiting factor. The effect of FSH on the meiosis-inhibiting activity of follicular cells was investigated by culturing COCs attached to the follicle wall and COCGs in the presence or absence of theca cells in medium containing FSH. Addition of 0.05 iu recombinant human $\mathrm{FSH} \mathrm{ml} \mathrm{m}^{-1}$ to the culture medium did not affect nuclear maturation and failed to overcome the suppressive effect exerted by the follicle wall or by theca cells, despite the fact that mRNA for the FSH receptor was found using RT-PCR in both cumulus and granulosa cells. These results demonstrate that the maintenance of meiotic arrest in equine oocytes during culture can be promoted by theca cells, which appear to act via a secreted inhibitory factor that cannot be suppressed or counteracted by FSH.

\section{Introduction}

Within preantral and immature antral ovarian follicles, mammalian oocytes remain arrested at the dictyate stage of the first meiotic division (Edwards, 1962). Further oocyte development does not begin until the follicle matures to the preovulatory stage and is stimulated by a luteinizing hormone (LH) surge, which induces maturation of the oocyte and ripening of the follicle. Once induced, oocyte maturation encompasses a complex series of molecular and structural events, beginning with the resumption of meiosis and germinal vesicle breakdown (GVBD) and culminating in the arrest of the oocyte at the second metaphase of meiosis (MII). However, when cumulus-oocyte complexes (COCs) are removed from their follicular environment and incubated

Email: J.Tremoleda@vet.uu.nl

†Deceased in vitro, meiosis resumes spontaneously (Pincus and Enzmann, 1935), indicating that factors present in the immature follicle are responsible for holding the oocyte in meiotic arrest. This hypothesis has been strengthened considerably by evidence that follicle cells can also inhibit the resumption of meiosis during culture. Within the follicle, an oocyte is linked physically and metabolically to the surrounding follicular cells by gap junctions that permit the direct transfer of messengers from the somatic cells of the follicle to the oocyte (Anderson and Albertini, 1976). However, when a COC is removed from its follicle by aspiration or scraping, these functional junctions between the COC and the follicle wall are broken down, thereby isolating the oocyte from the influence of the underlying membrana granulosa cells. Several studies have shown that contact between granulosa and cumulus cells enables the maintenance of meiotic arrest in vitro in both bovine (Carbonneau and Sirard, 1994; de Loos et al., 1994; 
Richard and Sirard, 1996a,b; Van Tol et al., 1996) and porcine oocytes (Motlik et al., 1991). Furthermore, the meiotic-arresting ability of granulosa cells appears to be enhanced by coculture with theca cells, at least for bovine oocytes (Kotsuji et al., 1994; Van Tol and Bevers, 1998).

Data on the role of follicular cells or FSH on the maintenance or cessation of meiotic arrest in equine oocytes are currently limited, although Hinrichs et al. (1995) reported that oocytes cultured with sections of follicle wall, sheets of membrana granulosa or within intact follicles, remained in meiotic arrest whereas oocytes cultured with follicular fluid or granulosa cells in suspension, did not.

There is also experimental evidence that FSH can modulate the meiosis-arresting activity of bovine granulosa cells. For example, Van Tol et al. (1996) found that adding $\mathrm{FSH}$ to oocyte culture medium prevented the meiotic arrest exerted by membrana granulosa cells. However, Carbonneau and Sirard (1994) found that FSH could not release bovine oocytes from meiotic arrest if they were cultured while still attached to their own follicle wall. Further studies indicate that theca cells can inhibit FSH-induced maturation of bovine oocytes (Kotsuji et al., 1994; Van Tol and Bevers, 1998), and a direct role for $\mathrm{FSH}$ in the resumption of meiosis has been supported by the demonstration of receptors for FSH in both cumulus and granulosa cells (Xu et al., 1995; Van Tol et al., 1996).

Certainly, in vitro maturation (IVM) of equine oocytes needs to be refined, and a better understanding of the factors that maintain an oocyte in meiotic arrest and regulate the resumption of nuclear maturation may help in the development of strategies to improve culture conditions with particular regard to the quality of cytoplasmic maturation (Sirard et al., 1998; Sirard, 2001). The present study was designed to examine the effect of the different types of cell in the follicle wall on the maintenance of meiotic arrest in cultured equine oocytes, and to evaluate the effect of FSH on meiosisarresting activity. In addition, the reverse transcriptase polymerase chain reaction (RT-PCR) would be used to determine whether cumulus and granulosa cells from non-preovulatory follicles expressed mRNA for the FSH receptor.

\section{Materials and Methods}

\section{Collection and culture of oocytes}

Approximately 250 ovaries were collected immediately after slaughter from mares of unknown reproductive history during May to August (breeding season) of two consecutive years. Recovered ovaries were transported to the laboratory in a thermoflask at $25-30^{\circ} \mathrm{C}$ and, on arrival within $4 \mathrm{~h}$ after slaughter, ovaries were washed and immersed in $0.9 \%(\mathrm{w} / \mathrm{v}) \mathrm{NaCl}$ containing $10 \mathrm{iu}$ penicillin $\mathrm{ml}^{-1}$ and $10 \mu \mathrm{g}$ streptomycin $\mathrm{ml}^{-1}$ (both from Gibco Life Technologies, Breda). Cumulus-oocyte complexes (COCs) were recovered by aspiration from non-preovulatory follicles between 5 and $30 \mathrm{~mm}$ in diameter, as described by Tremoleda et al. (2001). Briefly, the contents of any visible follicle were aspirated and the follicle was flushed up to three times with PBS containing $50 \mathrm{mg} \mathrm{BSA} \mathrm{I}^{-1}$ (Sigma, St Louis, MO) and 25 iu heparin $\mathrm{ml}^{-1}$ (Leo Pharmaceutical, Weesp). Next, the ovaries were dissected and follicles situated deeper in the ovarian stroma were similarly aspirated and flushed. The recovered follicular fluid-PBS mixture was allowed to stand for about $10 \mathrm{~min}$ at room temperature and, after removing the supernatant, the resulting pellet was washed twice in Hepes-buffered Tyrode's medium supplemented with $0.1 \%(\mathrm{w} / \mathrm{v})$ polyvinylalcohol and $0.2 \%(\mathrm{w} / \mathrm{v})$ BSA. After resedimentation, the final pellet was collected and examined under a stereomicroscope to locate the COCs. Only oocytes with a complete, compact and multilayered cumulus investment (compact COCs: Hinrichs and Williams, 1997) and oocytes connected to a piece of homogeneous, multilayered membrana granulosa at least $0.25 \mathrm{~mm}^{2}$ in area (COCGs; Van Tol et al., 1996) were selected for culture. The selected COCs and COCGs were then washed twice with maturation medium and assigned randomly to treatment group before culture for $38 \mathrm{~h}$ in M199 medium supplemented with 100 iu penicillin $\mathrm{ml}^{-1}$ and $100 \mu \mathrm{g}$ streptomycin $\mathrm{ml}^{-1}$ (both Gibco), in four-well plates (Nunc A/S, Roskilde) maintained at $39^{\circ} \mathrm{C}$ in a humidified atmosphere of $5 \% \mathrm{CO}_{2}$ in air. In total, $\mathrm{COC}$ recovery and preparation for culture took $1-2 \mathrm{~h}$ so that COCs were in their final culture conditions between $4-6 \mathrm{~h}$ after slaughter of the mares.

Preparation of follicle wall pieces with or without an attached COC

Follicles were identified within recovered ovaries and dissected free of overlying ovarian connective tissue using a scalpel and forceps. Fine forceps were then used to strip away any remaining stromal tissue without rupturing the desired follicle. Follicles were selected on the basis of their size $(5-20 \mathrm{~mm}$ in diameter; larger follicles were technically difficult to dissect) and nonatretic appearance, as determined using the criteria of follicle wall transparency and vascularization (Kruip and Dieleman, 1982). In the follicles selected for culture, the COC was located using a dissecting microscope and the follicle was then pierced opposite to the COC to release the follicular fluid. The wall of the collapsed follicle was then trimmed around the COC $\left(2-3 \mathrm{~mm}^{2}\right)$ to obtain a COC with its attachment to the follicle wall (COCFW). Only COCsFW possessing a compact cumulus investment and a homogeneous membrana granulosa were selected for further culture. Similar sized pieces 
Table 1. Number (and percentage) of equine oocytes at given stages of nuclear maturation after in vitro culture with different follicular components

\begin{tabular}{|c|c|c|c|c|c|c|}
\hline \multirow{2}{*}{$\begin{array}{l}\text { Nuclear stage of } \\
\text { the oocyte }\end{array}$} & \multicolumn{6}{|c|}{ Maturation conditions } \\
\hline & COCsFW & $\mathrm{COCs}+\mathrm{FW}$ & COCGs & COCGs + theca & COCGs + $\mathrm{CM}_{\text {theca }}$ & COCs \\
\hline GV & $41(61)$ & $11(14)$ & $11(12)$ & $59(50)$ & $40(38)$ & $19(11)$ \\
\hline Metaphase I & 7 (10.5) & 7 (8.5) & $8(9)$ & $6(5)$ & $4(4)$ & $11(7)$ \\
\hline Metaphase II & $4(6)$ & $34(42.5)$ & $37(41)$ & $29(24)$ & $27(26)$ & $95(55)$ \\
\hline Degenerate & $15(22.5)$ & $28(35)$ & $34(38)$ & $25(21)$ & $34(32)$ & $46(27)$ \\
\hline Number of oocytes & 67 & 80 & 90 & 119 & 105 & 171 \\
\hline
\end{tabular}

COCsFW: individual cumulus-oocyte complexes (COCs) attached to their follicle wall; COCs + FW: COCs co-cultured with trimmed pieces of follicle wall; COCGs: COCs attached to a piece of membrana granulosa; COCGs + theca: COCGs co-cultured with sheets of theca cell; COCGs + $\mathrm{CM}_{\text {theca }}$ : COCGs cultured in theca cell conditioned medium; GV: germinal vesicle.

Total number of oocytes analysed $=632$. Average rate of oocyte degeneration across all culture conditions: $30 \pm 6.8 \%$ (mean \pm SD).

of follicle wall $\left(2-3 \mathrm{~mm}^{2}\right.$; FW) without a COC were prepared for co-culture with isolated COCs (COCs + FW).

\section{Isolation of theca cells and preparation of theca cell conditioned medium}

Non-atretic follicles between 5 and $20 \mathrm{~mm}$ in diameter were isolated from the ovaries as described above. The isolated follicles were then bisected with a scalpel to yield two hemifollicles from which the bulk of the granulosa cells were removed by scraping the inner wall. The removal of the granulosa cells was completed by vortexing the scraped hemifollicles for $1 \mathrm{~min}$ in $1 \mathrm{ml}$ Hepes-buffered M199 supplemented with $100 \mathrm{iu}$ penicillin $\mathrm{ml}^{-1}$ and $100 \mu \mathrm{g}$ streptomycin $\mathrm{ml}^{-1}$. The hemifollicles were then transferred to $1 \mathrm{ml}$ fresh medium, vortexed for a further minute and finally washed twice in $2 \mathrm{ml}$ of culture medium. In a preliminary experiment, histological analysis of ten hemifollicles prepared in this way demonstrated that no granulosa cells remained on the theca interna surface and, thus, that the procedure was effective for removing granulosa cells from the theca (Fig. 1).

Theca cell conditioned medium $\left(\mathrm{CM}_{\text {theca }}\right)$ was prepared by culturing three $3-5 \mathrm{~mm}^{2}$ sheets of theca cells (the three pieces covered roughly half of the floor of the $1.9 \mathrm{~cm}^{2}$ culture well) in $500 \mu \mathrm{l} \mathrm{M} 199$ medium supplemented with 100 iu penicillin $\mathrm{ml}^{-1}$ and $100 \mu \mathrm{g}$ streptomycin $\mathrm{ml}^{-1}$, in four-well plates (Nunc A/S) maintained at $39^{\circ} \mathrm{C}$ in a humidified atmosphere of $5 \%$ $\mathrm{CO}_{2}$ in air. After $38 \mathrm{~h}$ of culture, the conditioned medium was collected in Eppendorf tubes and centrifuged for $3 \mathrm{~min}$ at $11600 \mathrm{~g}$. The supernatant was collected and stored at $-20^{\circ} \mathrm{C}$ until subsequently used for oocyte maturation.

\section{Effect of follicular cells on oocyte nucleus maturation}

The effect of follicle wall components and theca cell conditioned medium on the progression of meiosis in equine oocytes during IVM was examined by culturing COCs in the following conditions (Fig. 2):

(1) Individual COCs attached to their follicle wall in $500 \mu \mathrm{l}$ culture medium (COCsFW: nine replicates, $n=67)$.

(2) Groups of 10-15 COCs cocultured with three to five pieces of trimmed follicle wall (COCs + FW: FW covered approximately one-third of the culture well floor) in $500 \mu \mathrm{l}$ culture medium (three replicates, $n=80)$.

(3) COCGs cultured in groups at a ratio of 1 per $100 \mu \mathrm{l}$ medium (six replicates, $n=90$ ).

(4) COCGs cocultured with three $3-5 \mathrm{~mm}^{2}$ theca cell sheets (covering approximately half of the culture well floor; COCGs + theca) in $100 \mu$ l medium per COCG (four replicates, $n=119$ ).

(5) COCGs in groups of five in $500 \mu \mathrm{l} \mathrm{CM}_{\text {theca }}$ (three replicates, $n=105$ ).

(6) COCs in groups of 25 in $500 \mu$ l of culture medium as a 'normal' IVM control (ten replicates, $n=171$ ).

The preparation of the various follicle components (Fig. 2) and the assignment of oocytes to treatments (Table 1 ) are summarized.

\section{Effect of FSH on the meiosis-arresting activity of follicular cells}

The following co-cultures were performed using culture medium (M199 containing 100 iu penicillin $\mathrm{ml}^{-1}$ and $100 \mu \mathrm{g}$ streptomycin $\mathrm{ml}^{-1}$ ) supplemented with 0.05 iu recombinant human $\mathrm{FSH} \mathrm{ml}^{-1}$ (rh-FSH-Org 32489: Organon, Oss), to determine whether FSH could alter the effects of follicular cells on cultured equine oocytes:

(1) COCs attached to their follicle wall (COCsFW) and cultured individually in $500 \mu \mathrm{FSH}$-supplemented medium (six replicates, $n=36$ ). 


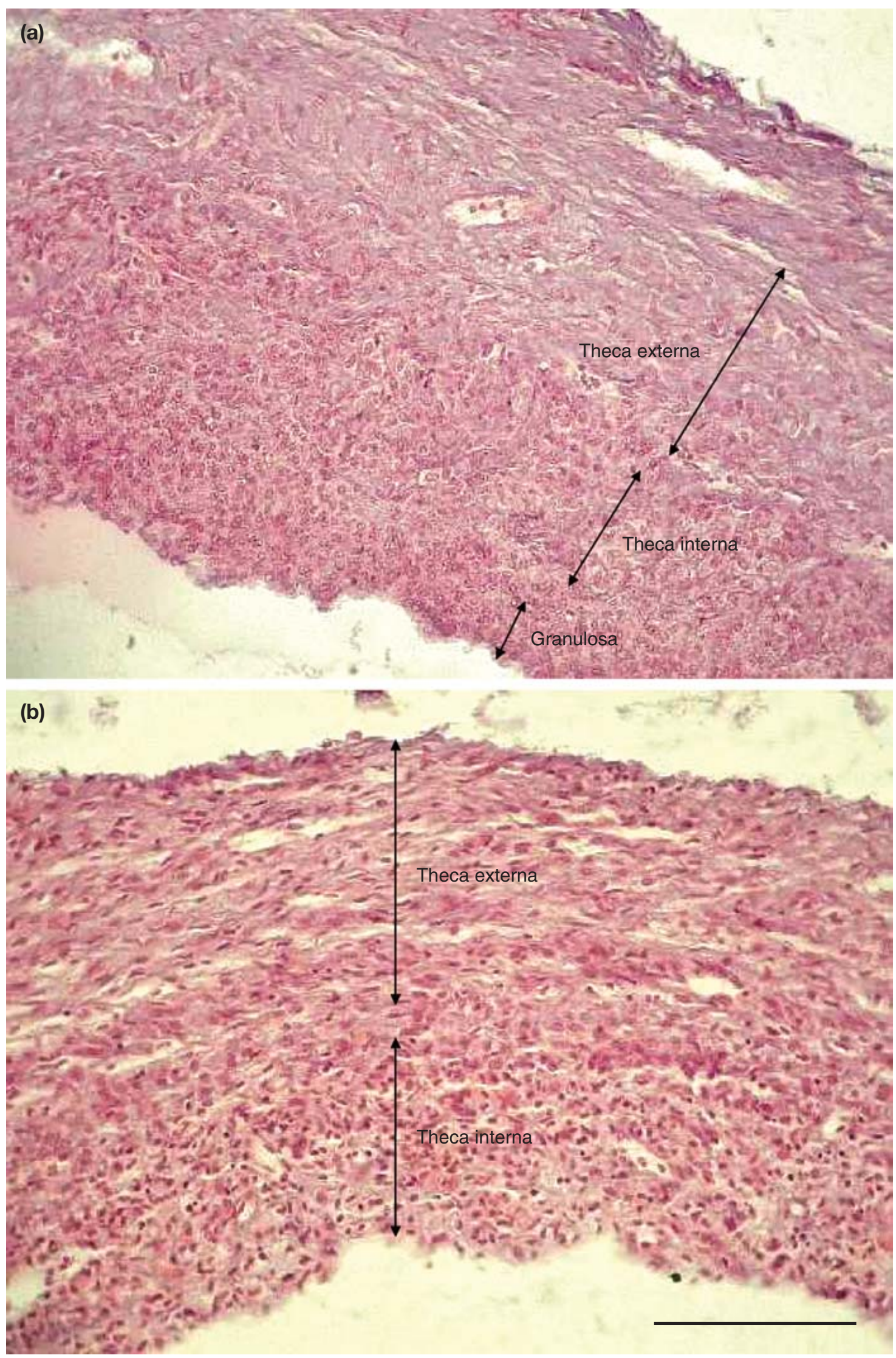

Fig. 1. For legend see facing page. 


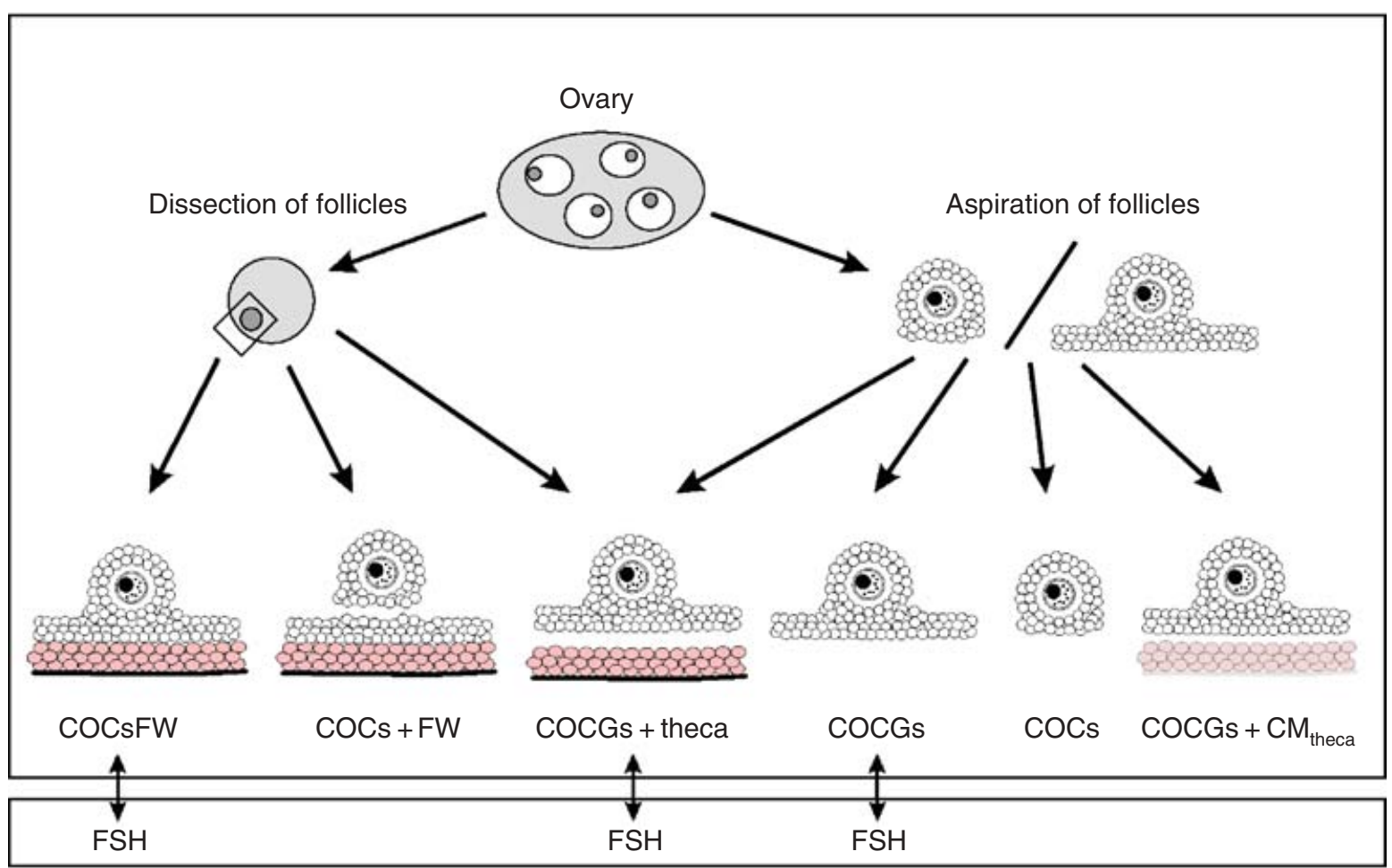

Fig. 2. Diagrammatic representation of the recovery of oocytes and the various follicle components to produce the culture conditions used in this study; that is, isolated cumulus-oocyte complexes (COCs) attached to their follicle wall (COCsFW); COCs + FW: COCs co-cultured with trimmed pieces of follicle wall; COCGs: COCs attached to a piece of membrana granulosa; COCGs + theca: COCGs co-cultured with sheets of theca cell; COCGs + CM $_{\text {theca }}$ : COCGs cultured in theca-cell conditioned medium FSH: supplementation of the culture medium with 0.05 iu recombinant human $\mathrm{FSH} \mathrm{ml}^{-1}$.

(2) COCGs in FSH-supplemented medium at a ratio of one COCG : $100 \mu$ l medium (six replicates, $n=89$ ).

(3) COCGs cocultured with three theca cell sheets (COCGs + theca) in $100 \mu \mathrm{l} \mathrm{FSH-supplemented} \mathrm{me-}$ dium per COCG (four replicates; $n=141$ ).

These incubations were performed contemporaneously with those in Expt 1 and, for the purposes of analysis, the latter were used as $\mathrm{FSH}$-free controls. The allocation of oocytes to experimental groups is summarized (Table 2).

\section{Assessment of stage of oocyte nucleus maturation}

At the end of the $38 \mathrm{~h}$ culture period, COCs were denuded by vortexing for $3 \mathrm{~min}$ in a $0.25 \%(\mathrm{v} / \mathrm{v})$ solution of trypsin in $\mathrm{CaCl}_{2}$ - and $\mathrm{MgCl}_{2}$-free Earle's balanced salt solution (EBBS; Gibco) containing 1 mmol EDTA I-1. The denuded oocytes were then washed three times in PBS before being fixed for $30 \mathrm{~min}$ at room temperature in $2 \%(\mathrm{w} / \mathrm{v})$ paraformaldehyde in PBS, and stored at $4^{\circ} \mathrm{C}$ until staining. Their nuclear status was assessed by first washing fixed oocytes twice in PBS and then incubating them in $0.1 \mu \mathrm{g}$ 4,6-diamino-2-phenyl-indole (DAPI) $\mathrm{ml}^{-1}$ in PBS for $5 \mathrm{~min}$, as described by Mori et al. (1988). Once stained, the oocytes were mounted on glass microscope slides and examined using a $\mathrm{BH} 2-\mathrm{RFCA}$ Olympus (Olympus, Tokyo) epifluorescence microscope equipped with a set of dichronic mirror unit (DMU) filters. Oocytes were classified as follows: (i) germinal vesicle (GV) stage, if their chromatin appeared either as a single condensed mass associated with the nucleolus (condensed chromatin) or diffusely or patchily throughout the nucleus (fluorescent nucleus), as described by Hinrichs et al. (1993); (ii) metaphase I (MI), encompassing all stages from germinal vesicle breakdown to formation of the first metaphase plate; (iii) metaphase II (MII), including all stages from anaphase I to formation of the second metaphase plate; (iv) degenerate oocytes, including oocytes with abnormal chromatin, chromatin spread throughout the ooplasm or with no visible chromatin, as described by Hinrichs et al. (1993).

Fig. 1. Photomicrographs of haematoxylin and eosin stained histological sections of hemifollicles before and after removal of the granulosa cells. (a) Intact follicle wall, displaying the theca externa and interna, with the granulosa cell layer on the luminal side of the follicle. (b) Follicle wall after treatment, displaying only the theca externa and interna without any visible granulosa cells. Scale bar represents $50 \mu \mathrm{m}$. 
Table 2. Number (and percentage) of equine oocytes at the different stages of nuclear maturation after in vitro culture with different follicle wall components in medium supplemented with 0.05 iu recombinant human $\mathrm{FSH} \mathrm{ml}^{-1}$

\begin{tabular}{lccr}
\hline & & \multicolumn{2}{c}{ Maturation conditions* } \\
\cline { 2 - 4 } Nuclear stage of oocyte & COCsFW + FSH & COCGs + FSH & COCGs + theca + FSH \\
\hline GV & $22(61)$ & $9(10)$ & $68(48)$ \\
Metaphase I & $1(3)$ & $2(2)$ & $11(8)$ \\
Metaphase II & $5(14)$ & $51(57.5)$ & $37(26)$ \\
Degenerate & $8(22)$ & $27(30.5)$ & $25(18)$ \\
Number of oocytes & 36 & 89 & 141
\end{tabular}

*COCsFW: individual COCs attached to their follicle wall; COCGs: COCs attached to membrana granulosa; COCGs + theca: COCGs cocultured with sheets of theca cell; GV: germinal vesicle. For the purpose of analysis, the equivalent FSH-free treatments carried out contemporaneously in Expt 1 were used as controls. The total number of oocytes analysed for this experiment was thus 572 (266 with FSH and 276 in control conditions). The average rate of oocyte degeneration for all oocytes cultured in the presence of FSH was $25 \pm$ $6.3 \%($ mean $\pm \mathrm{SD})$.

\section{Collection of tissue for total RNA extraction and reverse transcription}

COCs with a compact multilayered cumulus investment and compact pieces of membrana granulosa at least $0.25 \mathrm{~mm}^{2}$ in area were selected from follicular contents harvested by aspiration. Cumulus cells were then harvested from the COCs by repeated aspiration through a narrow-bore Pasteur pipette. Next, the collected granulosa or cumulus cells were washed four times in PBS, loaded into Eppendorf tubes and stored at $-80^{\circ} \mathrm{C}$ until RNA extraction. Each tube contained one piece of membrana granulosa or the cumulus cells from ten COCs.

Isolation of total RNA was performed using the RNeasy Mini Kit according to the manufacturer's instructions (Qiagen, Valencia). After elution in $30 \mu \mathrm{l}$ RNAse-free water, the concentration of extracted total RNA was determined using a Gene Quant 2 (Pharmacia Biotech, serial no. 61708) and adjusted to $0.3 \mu \mathrm{g}$ per $10 \mu \mathrm{l}$. Before the reverse transcription reaction, the RNA sample was incubated for 5 min at $70^{\circ} \mathrm{C}$, vortexed for $5 \mathrm{~s}$ and chilled on ice. Reverse transcription was performed in a total volume of $20 \mu \mathrm{l}$, made up of $10 \mu \mathrm{l}$ sample RNA, $4 \mu \mathrm{l}$ of $5 \times$ reverse transcriptase buffer (Gibco BRL, Breda), $8 \mathrm{U}$ RNAsin (Promega), $150 \mathrm{U}$ Superscript II reverse transcriptase (Gibco BRL), $0.036 \mathrm{U}$ random primers (Life Technologies BV, Leiden), 10 mmol dithiothreitol $\mathrm{I}^{-1}$ and each dNTP at final concentrations and $0.5 \mathrm{mmol} \mathrm{I}^{-1}$, respectively. The mixture was incubated for $1 \mathrm{~h}$ at $42^{\circ} \mathrm{C}$ and then for $5 \mathrm{~min}$ at $95^{\circ} \mathrm{C}$ before being stored at $-20^{\circ} \mathrm{C}$. $\mathrm{RT}$-free blanks were prepared using the same conditions but excluding the reverse transcriptase.

\section{Amplification of FSH receptor $C D N A$ by $P C R$}

The oligonucleotide primers used for amplifying the FSH receptor (FSHR) mRNA were based on a previously published donkey FSHR mRNA sequence (Richard et al., 1997). Amplification of RNA from membrana granulosa and cumulus cells was performed in two stages. For the first round of amplification, the FSHR-primers used were: FSHRL2 (5'-CTTGCCAGCTGTTCACAAGA-3'; sense, position 402-421) and FSHRR1 (5'-TCAGGATCACCAGCACTATG-3'; antisense, position 1119-1138). A second round of PCR using nested primers was then performed to increase the specificity of the final product. The second round primers were: FSHRL4 (5'-GTTGCACTCATGGAGGCCAG-3'; sense, position 784-803) and FSHRR4 (5'-CCAGTGATGGCTAGGATGCT-3'; antisense, position 1093-1112). Reactions were carried out in $200 \mu \mathrm{l}$ tubes (Eurogentec, Seraing), using $1 \mu \mathrm{l} \mathrm{cDNA}$ as a template for $25 \mu \mathrm{l}$ of the PCR mixture, which contained $2 \mathrm{mmol}^{\mathrm{MgCl}} \mathrm{I}^{-1}$, $100 \mu \mathrm{mol} \mathrm{I}^{-1}$ of each dNTP, $0.5 \mu \mathrm{mol} \mathrm{I}{ }^{-1}$ of each primer and $0.625 \cup$ Taq DNA polymerase (HotStarTaq, Qiagen, Valencia) in $1 \times$ PCR buffer. The thermal cycling profile for the first round was: initial denaturation and activation of the polymerase for $15 \mathrm{~min}$ at $94^{\circ} \mathrm{C}$, followed by 40 cycles of $15 \mathrm{~s}$ at $94^{\circ} \mathrm{C}, 30 \mathrm{~s}$ at $55^{\circ} \mathrm{C}$ and $45 \mathrm{~s}$ at $72^{\circ} \mathrm{C}$. Final extension was for $10 \mathrm{~min}$ at $72^{\circ} \mathrm{C}$. For nesting, $1 \mu \mathrm{l}$ of the first-round product was transferred to another $200 \mu \mathrm{l}$ tube containing $24 \mu \mathrm{l}$ PCR buffer and amplified for 30 cycles using the same thermal profile. All PCRs were performed in a 24-well thermocycler (Perkin-Elmer, Gouda). The PCR products were identified by resolving $10 \mu \mathrm{l}$ of the second-round product on a $1 \%$ Agarose gel containing $0.4 \mu \mathrm{g}$ ethidium bromide $\mathrm{ml}^{-1}$. A $100 \mathrm{bp}$ ladder (Gibco BRL) was included as a reference for fragment size and an image of the gel was taken using a CCD camera (Appligene, B \& L Systems, Zoetermeer) and stored in digital form. The second round product from the granulosa cell-PCR was purified using the QIAquick ${ }^{\circledR}$ PCR purification kit (Qiagen, Valencia) and sequenced (Eurogentec, Seraing).

\section{Statistical analysis}

For the purpose of analysis, oocytes were first classified either as GV (that is remaining in meiotic arrest) or GVBD (that is, oocytes that resumed meiosis, 


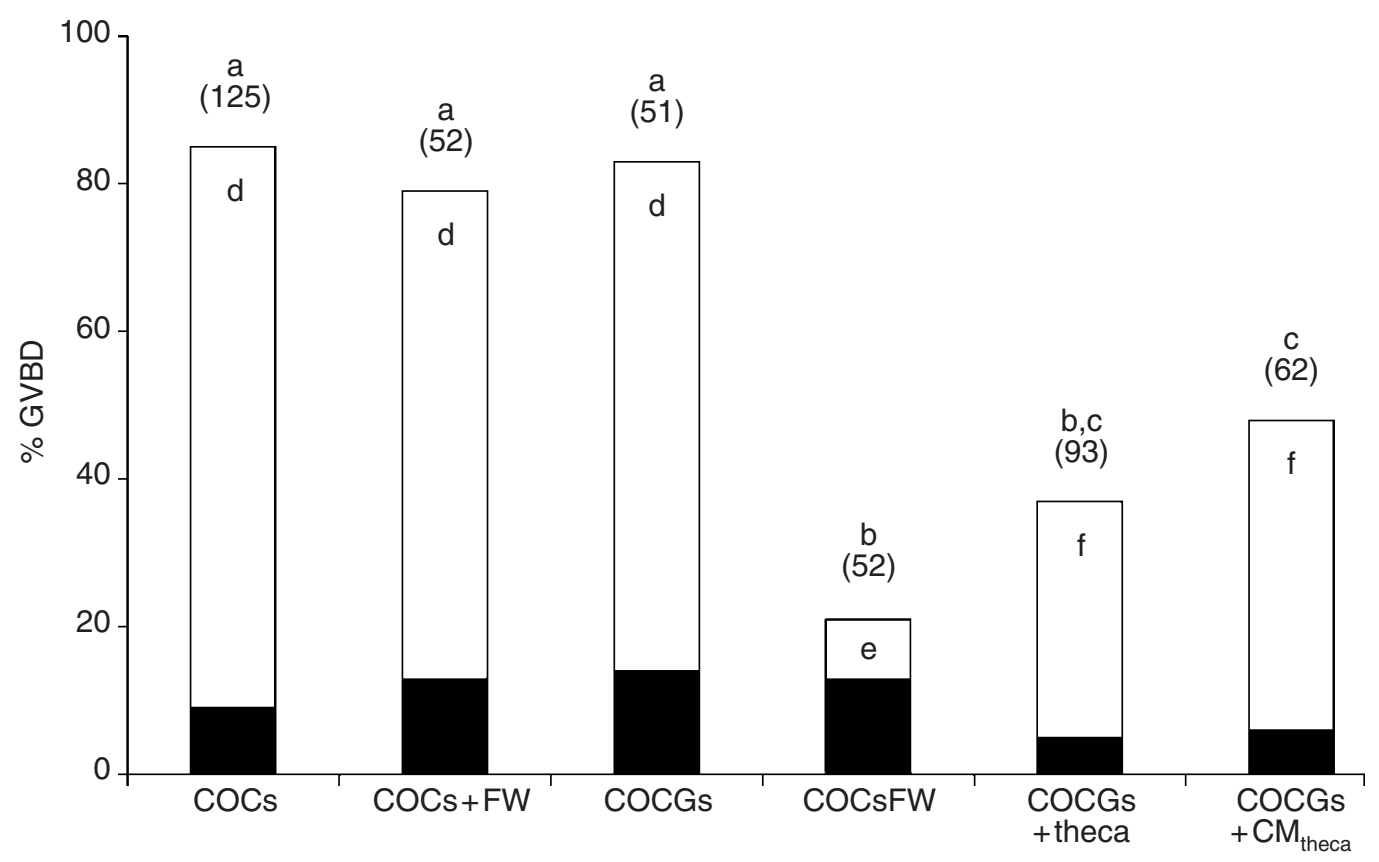

Fig. 3. The effect of follicle components on the progression of meiosis by equine oocytes during in vitro maturation. Oocytes were cultured for 38 h in M199 as cumulus-oocyte complexes (COCs), COCs attached to the follicle wall (COCsFW), COCs coincubated with pieces of follicle wall (COCs + FW), COCs connected to a piece of membrana granulosa (COCGs), COCGs in the presence of theca cells (COCGs + theca) and COCGs in theca-cell conditioned medium $\left(\mathrm{CM}_{\text {theca }}\right)$. The number of oocytes analysed is indicated above each column in parentheses, at $\mathrm{MI}(\boldsymbol{\square})$ or MII $(\square)$ stages. ${ }^{\text {a,b,c }}$ Bars with different letters differ significantly with regard to the percentage of oocytes that underwent germinal vesicle breakdown (GVBD) $(P<0.05$, logistic regression). ${ }^{\mathrm{d}, \mathrm{e}, \mathrm{f}}$ Different letters indicate a significant difference in the percentage of GVBD oocytes reaching the MII stage during culture $(P<0.05$, logistic regression). Degenerate oocytes were excluded from these analyses.

irrespective of how far they then progressed). GVBD oocytes were then further subdivided into how far they had progressed through nuclear maturation (MI or MII). The effects of the different culture conditions and the addition of FSH on the proportion of oocytes that underwent GVBD and the proportion of GVBD oocytes that reached metaphase II were analysed using SPSS software (SPSS, Chicago, IL) and logistic regression analysis (McCullagh and Nelder, 1989) for binomially distributed data. Culture conditions and the presence of FSH were considered as independent categorical variables in this model and $P<0.05$ was taken to indicate a statistically significant difference. Where differences existed, further comparison of groups was performed by chi-squared analysis to indicate the source of the differences $(P<0.05)$.

\section{Results}

In Expt 1, approximately 30\% of the 632 oocytes cultured were categorized as degenerate after culture and were excluded from further calculations (Table 1). The majority $(79 \%)$ of oocytes from COCs cultured while still attached to a piece of their follicle wall (COCsFW) were still in the GV stage at the end of culture (Fig. 3). By contrast, only $21 \%(P<0.005)$ of oocytes remained in meiotic arrest when COCs were cocultured with separate pieces of follicle wall. Indeed, the percentage of oocytes that underwent GVBD did not differ between COCs + FW and control, isolated COCs ( 79 versus $85 \%$; Fig. 3), and in both conditions most GVBD oocytes reached the MII stage (83 and $89 \%$ of GVBD oocytes, respectively). COCs cultured while adhered to just the membrana granulosa (COCGs) also underwent GVBD and nuclear maturation at a similar rate to control COCs (80\% GVBD of which $82 \%$ reached MII). However, when COCGs were cultured in the presence of thecal tissue (COCGs + theca), the percentage of oocytes that remained arrested at the GV stage was significantly higher than when COCGs were cultured alone (63 versus $20 \%$ ) and similar to that observed for the COCsFW group (79\%: Fig. 3). Furthermore, oocytes cultured as COCGs in $\mathrm{CM}_{\text {theca }}$ maintained meiotic arrest at a similar rate to COCGs cultured with thecal tissue (56 versus $63 \%$ ). Nevertheless, the percentage of oocytes that underwent GVBD during culture as COCGs in $\mathrm{CM}_{\text {theca }}$ was significantly higher than that for COCsFW (44 versus $21 \% ; P<0.005 ;$ Fig. 3 ) and, of the oocytes that 


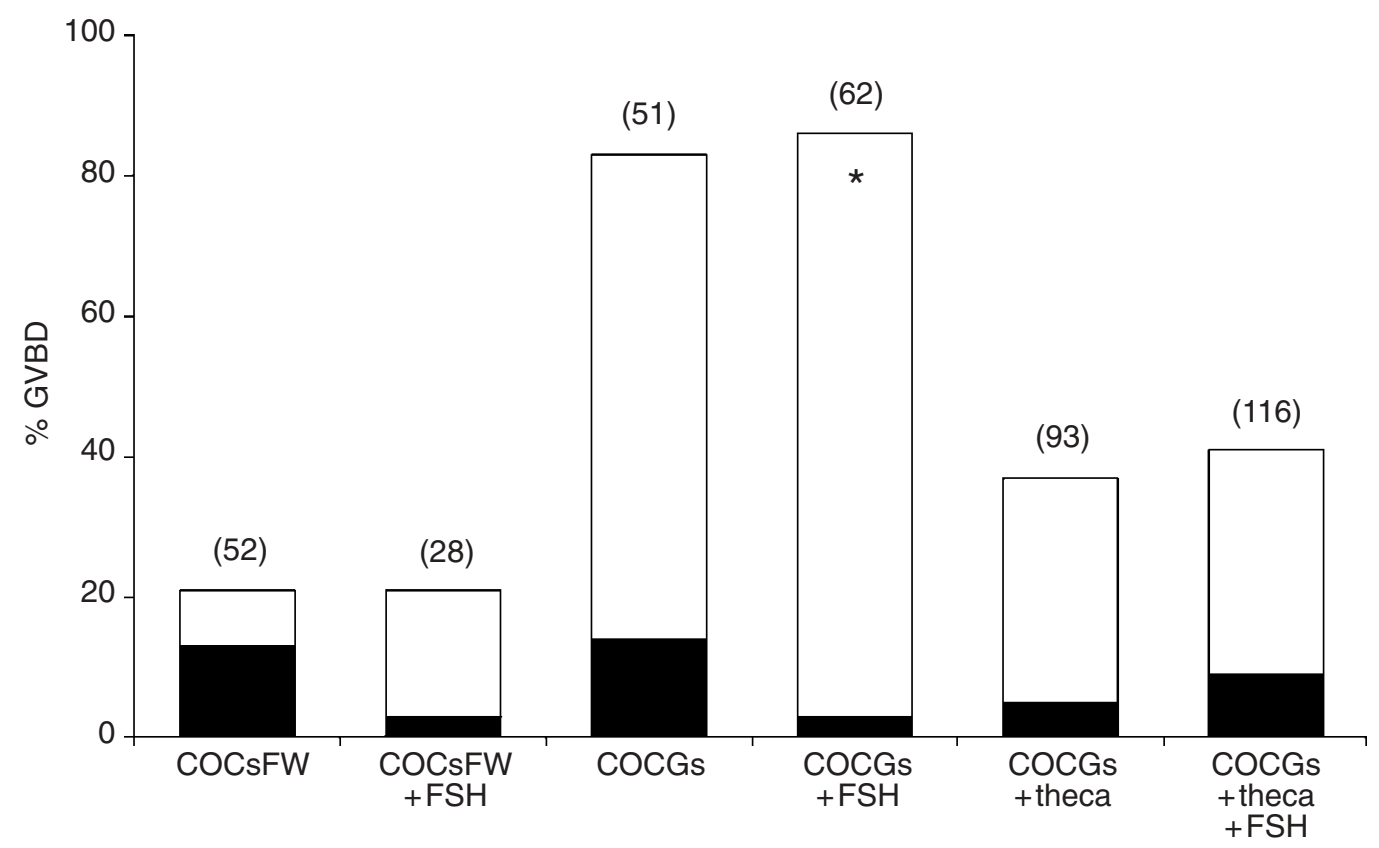

Fig. 4. The effect of FSH on the resumption of meiosis by equine oocytes during in vitro maturation. Oocytes were cultured in M199 with or without 0.05 iu recombinant human FSH for 38 h, in the form of cumulus-oocyte complexes (COCs) attached to their follicle wall (COCsFW) or COCs connected to a piece of membrana granulosa (COCGs) either in the presence or absence of theca cells. The number of oocytes in each experimental group is indicated above each column in parentheses, at MI (ם) or MII ( $\square$ ) stages. FSH treatment did not significantly affect the proportion of oocytes that underwent germinal vesicle breakdown (GVBD) $\left(P>0.05\right.$; logistic regression). ${ }^{*}$ Indicates the FSH treated group that differed from the corresponding $\mathrm{FSH}$-free control in terms of the percentage of GVBD oocytes that reached MII $(P<0.05$, Chi-square test). Degenerate oocytes were excluded from these analyses.

underwent GVBD, significantly more reached the MII stage after culture of COCGs in $\mathrm{CM}_{\text {theca }}$ than after culture attached to the follicle wall (87 versus $36 \% ; P<0.005$; Fig. 3).

In Expt 2, a total of 572 oocytes was cultured with different follicle components in the presence or absence of FSH (Table 2). Similarly to Expt 1, approximately $25 \%$ of the oocytes were categorized as degenerate after culture and were excluded from further analysis. In general, addition of 0.05 iu recombinant human $\mathrm{FSH}$ failed to influence the number of oocytes that resumed meiosis. For example, the percentage of GVBD oocytes after culture of COCGs in medium supplemented with FSH was similar to that for COCGs cultured without $\mathrm{FSH}$ (86 versus $80 \%$; Fig. 4). However, the percentage of GVBD oocytes that reached the MII stage was, in many cases, increased significantly by FSH (for example $82 \%$ for COCGs versus $96 \%$ for COCGs plus FSH; $P<0.05$; Fig. 4). Similarly, for oocytes cultured as COCsFW or COCGs + theca, addition of FSH did not increase the proportion of oocytes achieving GVBD (COCsFW: 79 versus $79 \%$; COCGs + theca: 59 versus $63 \%$ for plus and minus FSH incubations, respectively; Fig. 4) but did tend to increase the proportion of oocytes from COCsFW

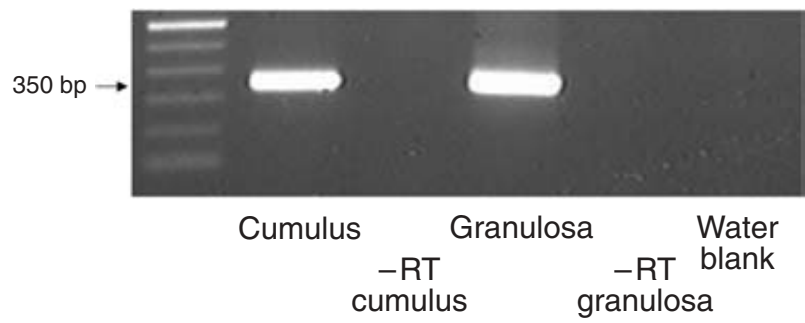

Fig. 5. Expression of equine FSH receptor as detected by RT-PCR. The PCR products of $350 \mathrm{bp}$ were produced using FSH receptorspecific primers in two rounds of amplification. The source of samples subjected to PCR are indicated at the bottom and a $100 \mathrm{bp}$ ladder is included in the far left-hand lane as a marker for fragment size.

that reached the MII stage (83 versus 36\% for plus and minus FSH groups). However, addition of FSH to COCGs cocultured with theca cells did not affect the number of GVBD oocytes reaching MII.

Amplification of cDNA from granulosa and cumulus cells using FSHR-specific primers resulted in one abundant PCR product after the two rounds of amplification, whereas amplification of RT blanks and the water control yielded no specific products (Fig. 5). 
FSHRbovine FSHRdonkey FSHRrat FSHRmouse SEQhorse

FSHRbovine FSHRdonkey FSHRrat FSHRmouse SEQhorse

FSHRbovine FSHRdonkey FSHRrat FSHRmouse SEQhorse

FSHRbovine FSHRdonkey FSHRrat FSHRmouse SEQhorse

FSHRbovine FSHRdonkey FSHRrat FSHRmouse SEQhorse

FSHRbovine FSHRdonkey FSHRrat FSHRmouse SEQhorse

FSHRbovine FSHRdonkey FSHRrat FSHRmouse SEQhorse
CCTCACCTACCCCAGCCACTGCTGTGCCTTTGCAAACTGGAGGCGGC CCTCACCTACCCCAGCCATTGCTGTGCCTTTGCAAACTGGAGACAAC CCTCACCTACCCCAGCCACTGCTGTGCTTTTGCAAACTTGAAGCGGC CCTTACCTACCCCAGTCACTGCTGTGCCTTTGCAAACTGGAGGCGGC TTCCACCTACCCCAGCCATTGCTGTGCCTTTGCAAACTGGAGACGAC

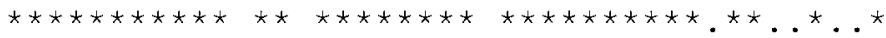

AАACСTCTGACCTTCATCCAATTTGCAACAAATCTATTTTAAGGCAAGAA AAACCTCTGAGCTTCAGACAACTTGCAACAAATCTATTTTAAGGCAAGAA AAATCTCTGAACTTCATCCAATTTGCAACAAGTCTATTTTAAGGCAAGAT AAACCTCTGAACTTCATCCAATTTGCAACAAGTCTATTTCAAGGCAAGAT AAACCTCTGAGCTTCAGACAACTTGCAACAAATCTATTTTAAgGCAAGAA

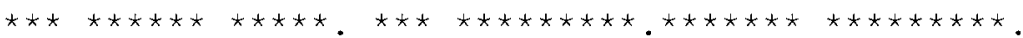

GTTGATGACATGACTCAGGCTAGGGGTCAGAGAGTCTCTTTGGCAGAAGA GTTGAT---ATGACTCAGGCTAGGGGTGAGAGAGTCTCTTTGGCAGAGGA ATTGATGATATGACTCAAATTGGGGATCAGAGAGTCTCTCTGA---TAGA ATTGATGATATGACTCAGCCTGGGGATCAGAGAGTCTCTCTCG---TAGA GTTGAT---ATGACTCAGGCTAGGGGTGAGAGAGTCTCTTTGGCAGAAGA .***** $* * * * * * * * . \quad * . * * * . * * * * * * * * * * * * * . . . * *$

TGATGAGCCCAGCTATGCCAAAGGATTTGACGTGATGTACAGTGAATTTG CGATGAGTCCA------------------TGATGTACAGTGAATTTG TGATGAACCCAGTTATGGAAAAGGATCTGACATGATGTACAATGAATTTG TGATGAACCCAGTTATGGAAAAGGATCTGACATGTTGTATAGTGAATTTG TGATGAGTCCAGTTACCCCAAAGGATTTGACATGATGTACAGTGAATTTG

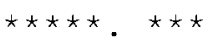

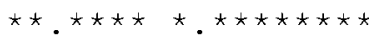

ACTATGACTTATGCAATGAAGTGGTTGATGTGACTTGCTCCCCTGAGCCA ACTATGACTTATGCAACGAAGTCGTTGATGTGACTTGCTCCCCCAAGCCA ATTATGACTTATGTAATGAAGTTGTTGATGTGACCTGCTCACCAAAGCCA ACTATGACTTATGCAATGAATTTGTTGATGTGACCTGCTCGCCAAAGCCA AGTATGACTTATGCAACGAAGTCGTTGATGTGACTTGCTCCCCCAAGCCA

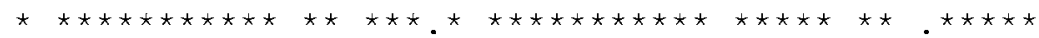

GACGCATTTAATCCATGTGAAGATATCATGGGGGATGATATTCTCAGAGT GATGCATTTAATCCATGTGAAGATATCATGGGGTATGATATTCTCAGAGT GATGCATTTAATCCATGTGAAGATATCATGGGGTACAACATCCTCAGGGT GATGCATTTAATCCATGTGAAGACATCATGGGGTACAACATCCTCAGAGT GATGCATTCAATCCATGTGAAGATATCATGGGGTATGATATTCTCAGAGT

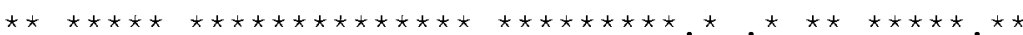

CTTGATATGGTTTATT CTTGATATGGTTTATA CTTGATATGGTTTATT CTTGATATGGTTTATC CTTGATATGGTTTATT
1116 1092 1113 1113

850

850

850

850

47

900

900

900

900

97

950

947

947

947

144

1000

976

997

997

194

1050

1026

1047

1047

244

1100

1076

1097

1097

294

310

Fig. 6. Sequence of the amplified equine FSH receptor product (SEQhorse) and its similarity to corresponding sequences in cow, donkey, rat and mouse. The donkey FSH receptor cDNA lacks 21 nucleotides corresponding to positions 156-176 of the sequenced horse product. *Denotes nucleotides in the sequence that are conserved across all species compared.

The PCR product contained $350 \mathrm{bp}$ and sequence analysis of the FSHR band amplified from granulosa cells demonstrated $90.0 \%$ identity to donkey FSHR mRNA. The major difference was the presence of 21 nucleotides in positions 155-175 that were absent from the donkey sequence described by Richard et al. (1997). This difference explained the difference in sequence length between the obtained $350 \mathrm{bp}$ product and the 
329 bp donkey sequence. Comparison of the sequenced equine FSHR product with FSHR mRNA from cattle, rats and mice showed 91.6, 83.2 and $83.5 \%$ similarity, respectively, with no deletions in the section corresponding to positions 155-175 in the amplified product (Fig. 6).

\section{Discussion}

The major finding of this study was that the spontaneous resumption of meiosis by equine oocytes cultured in vitro was inhibited when cumulus-oocyte complexes were cultured while still connected to their follicle wall, or when COCs connected to a piece of membrana granulosa were co-cultured with theca cells or in theca cell-conditioned medium. This finding supports strongly the hypothesis that some components of the follicle wall or, more specifically, some product(s) of the theca cells are essential for maintaining the oocyte in meiotic arrest in horses, as in other mammalian species (Leibfried and First, 1980; Sirard and Coenen, 1993; De Loos et al., 1994). Moreover, in this study FSH was not able to overcome the meiosis-arresting effect exerted by follicle wall or theca cells. Interestingly, the inhibitory effect, which was apparently a function of the theca cells, clearly depended on the maintenance of cellto-cell contact between the cumulus-oophorus and the granulosa cells since, when COCs were cultured with separate pieces of follicle wall, most oocytes underwent GVBD (79\%), whereas when COCs were cultured attached to their follicle wall, most oocytes remained arrested in GV (79\%). Similarly, when whole hamster follicles are cultured, close contact between the COC and granulosa cells appears to be central to the maintenance of oocyte meiotic arrest (Racowsky and Badwin, 1989), and bovine oocytes can be maintained in the GV stage in vitro by culturing COCs with undisrupted contact to the follicle wall (Carbonneau and Sirard, 1994; De Loos et al., 1994). In horses, Hinrichs et al. (1995), previously reported that meiotic arrest was maintained when isolated COCs were cultured with sections of follicle wall, or when they were injected into and cultured within intact isolated follicles. By contrast, in the current study, meiotic arrest was not maintained when isolated COCs were co-cultured with pieces of follicle wall. The marked difference in outcome presumably relates to the different culture conditions used. In the study of Hinrichs et al. (1995), groups of at least 30 COCs were co-cultured with three to four $5 \mathrm{~mm}^{2}$ sheets of follicle wall in $50 \mu \mathrm{l}$ of culture medium (M199) supplemented with 10\% neonatal calf serum. In the present study, groups of 10-15 COCs were co-cultured with three to five $2-3 \mathrm{~mm}^{2}$ sheets of follicle wall in $500 \mu \mathrm{l}$ of medium (M199). The difference in the medium volume: amount of follicle wall tissue ratio could conceivably have compromised the metabolic activity of the oocytes and their ability to progress through meiotic maturation. More likely, the different tissue: medium ratio would have significantly altered the concentration of follicle wall inhibitory factors to which oocytes were exposed during coculture (Sirard and Coenen, 1993). The fact that the proportion of degenerate oocytes after co-culture with pieces of follicle wall did not differ from that after culture of isolated COCs $(22.5 \%$ for COCsFW group versus $27 \%$ for the COCs group; $P>0.05)$ indicates that the tissue:culture medium ratio used did not markedly impair either the viability of cultured oocytes or their ability to progress through meiosis. Nevertheless, whether the failure of separated follicle wall to prevent meiotic resumption in the current study was due to dilution of inhibitory factors in the culture conditions used or failure of signal transmission due to loss of the intercellular junctions between the COCs and the adjacent follicle wall (Kotsuji et al., 1994) requires further investigation.

This study revealed that spontaneous resumption of meiosis by equine oocytes in vitro is effectively inhibited when cumulus-oocyte complexes attached to membrana granulosa are cultured in the presence of theca cells, whereas granulosa alone failed to induce this suppression. The critical role of theca cells in the maintenance of meiotic arrest in bovine oocytes has been studied extensively (Kotsuji et al., 1994; Richard and Sirard, 1996a,b; Van Tol and Bevers, 1998, 2001) and, in cattle, it is clear that there is a synergistic effect of theca cells on the meiosis-modulating activity of granulosa cells, such that the inhibitory action of theca cells is much more effective on COCGs than on COCs. Unfortunately, information on the effect of theca cells on horse oocytes cultured in vitro is scarce. Okólski et al. (1993) examined the rate of nuclear maturation in equine oocytes with a compact cumulus that were co-cultured with theca interna or granulosa cells, and found no effect of either on the number of oocytes reaching metaphase II, although follicular cells did influence cumulus expansion. Choi et al. (2002) similarly reported that co-culture with theca cells did not increase the likelihood of successful nuclear maturation for compact COCs. However, in both of these studies, FSH, LH or oestradiol were added to the culture medium, and it is therefore difficult to interpret definitively whether follicular cells had any modulatory effect on oocyte maturation. In short, the data presented in the current study are the first experimental evidence that theca cells are important to the maintenance of meiotic arrest in equine COCs connected to membrana granulosa.

Bovine (Van Tol et al., 1996) and porcine (Motlik et al., 1991) COCs cultured with an attached piece of membrana granulosa do not resume meiosis. In horses, Hinrichs et al. (1995) reported that cells in suspension could not maintain meiotic arrest whereas dissected sheets of mural granulosa cells layers could. It must be presumed that this difference in response was due 
either to the relative number of granulosa cells included in the cultures, or to the method of granulosa cell preparation, and it is possible that remaining theca cells or other follicle components on the dissected granulosa cell layers were responsible for the observed suppression. In a similar vein, the fact that the cumulus oophorus is more firmly attached to the follicle wall in horses than in other species (Ginther, 1992) presumably affects not only the oocyte recovery rate after follicle aspiration but also the quality and quantity of follicle components recovered with the COCs. For example, the cumulus granulosa cells surrounding an equine oocyte are broadly distributed and are connected to the outermost layer of mural granulosa cells via a loose network of intercellular spaces (Brück et al., 1999). This particular oocyte-follicle connection may compromise the recovery of large pieces of mural granulosa cell tissue when COCGs are isolated from the follicle and this may, in turn, lower the overall meiosis-inhibiting ability of attached granulosa cells. Thus, it is possible that in the current study, the failure of pieces of membrana granulosa attached to the COCs to suppress nuclear maturation was due to an insufficient quantity of mural granulosa cells. This would also help to explain why meiotic arrest was not maintained in cultured equine COCGs, but is in bovine or porcine COCGs. Further examination of the function of granulosa and cumulus cells in horses may help to elucidate their specific functions in modulating meiotic activity of the oocyte. Despite the apparent lack of a direct meiosis-inhibiting effect, granulosa cells did appear to play an important modulating role in the meiotic arresting activity of other follicular cells, namely the theca cells. A synergism between granulosa and theca cells has been reported in other species (Tsafiri and Channing, 1975; Van Tol and Bevers, 1998) and it appears that cellular contact between granulosa and cumulus cells is important for maintaining an oocyte in the GV stage during culture (Sato et al., 1982).

In the present study, oocytes cultured as COCGs in $\mathrm{CM}_{\text {theca }}$ maintained meiotic arrest at a similar rate to those cultured as COCGs with pieces of theca, thereby indicating that the inhibitory effect is exerted via a factor produced and secreted by the theca cells. In this respect, Van Tol and Bevers (1998, 2001) characterized the meiosis-inhibiting factor(s) produced by bovine theca cells as a small, stable, polar, non-peptide molecule that acts via the cumulus cells (Richard and Sirard, 1996b) but the identity of which remains to be elucidated. The current results indicate that equine theca cells also produce a meiosis-inhibiting factor, although the efficacy of meiosis suppression by theca cells or theca cell conditioned medium was lower than that by attached follicle wall (21\% GVBD for COCsFW versus 37 and $45 \%$ for COCGs + theca and COCGs + $\mathrm{CM}_{\text {theca, }}$, respectively). Furthermore, of the oocytes that did resume meiosis, fewer from the COCsFW group reached MII within the
$38 \mathrm{~h}$ culture period than from the other two groups (36\% for COCsFW versus $86 \%$ for COCGs + theca and $87 \%$ for COCGs $\left.+\mathrm{CM}_{\text {theca }}\right)$. These differences in the rate of maintenance of meiotic arrest may, as previously discussed, be associated with the relative paucity of membrana granulosa tissue in COCGs compared with COCs dissected with their follicle wall attachment. If so, this indicates that inhibition can properly be achieved by the theca cell meiosis-inhibiting factor(s) only when large quantities of viable granulosa cells are present.

With regard to the effect of FSH on the meiosisinhibiting activity of follicular cells during culture, this study demonstrated that $\mathrm{FSH}$ cannot reverse the inhibitory action of contiguous follicle wall or of theca cells acting via a granulosa layer attached to the COC. However, FSH did significantly increase the proportion of reactivating oocytes that reached the MII stage during the $38 \mathrm{~h}$ culture period. Previous studies on bovine oocytes showed similarly that treatment with gonadotrophic hormones could not reverse the inhibitory action of follicle wall on meiotic resumption when oocytes were cultured within their own half-follicles (Carbonneau and Sirard, 1994) or as COCGs co-cultured with theca cells. However, FSH did stimulate the resumption of meiosis in oocytes cultured as COCGs in the absence of thecal tissue (Van Tol et al., 1996). In the present study, when equine COCGs were cultured in the presence of $\mathrm{FSH}$, the percentage of GVBD oocytes that reached MII was increased and there appeared to be an increase in the extent of cumulus expansion, when compared with COCs cultured without FSH. That FSH might be expected to affect equine oocyte maturation and cumulus expansion was supported by the detection of mRNA for the FSH receptor in cumulus and membrana granulosa cells recovered from $10-20 \mathrm{~mm}$ follicles. Together with previous studies that used ligand binding and immunocytochemistry to demonstrate that specific FSH receptors are present within equine follicles (Stewart and Allen, 1979; Fay and Douglas, 1987), this finding confirms the production and expression of the FSH receptor in small equine follicles.

In addition to its inability to overcome the meiosisinhibiting effect of theca cells during IVM, FSH also failed to improve the MII rate of those oocytes that did undergo GVBD in the presence of theca cells. By contrast, FSH treatment resulted in a better progression of GVBD oocytes to MII for COCGs, and a similar tendency was observed for COCsFW, all of which indicates that theca cells may also interfere with the progression of meiosis in oocytes already committed to meiotic resumption. Similarly during IVM of bovine oocytes, theca cells antagonize the effect of FSH on COCGs and suppress the number of oocytes resuming meiosis and halt the majority that do resume GVBD at MI (Van Tol and Bevers, 1998, 2001). The inhibitory effects of theca cell secreted factor(s) may include interfering with activation of the 
maturation promoting factor (MPF), a complex of cyclin $B$ and p34 ${ }^{\text {cdc2 }}$ kinase; activation depends on specific phosphorylation and dephosphorylation of the p34 ${ }^{\text {cdc2 }}$ kinase (Coleman and Dunphy, 1994). For GVBD to occur, MPF has to be initially inactivated to regulate the G2 to $M$ transition of oocytes and then reactivated to regulate the M phase (Epping et al., 1996). Arrest of oocytes at MI may be related to failure of MPF activity to recover after the first metaphase, since this is necessary for progression from MI to MII. Indeed, insufficient MPF activity has been associated with failure of partially competent oocytes recovered from juvenile females to proceed through $\mathrm{Ml}$; in these oocytes, the amount of p34 $4^{\text {cdc2 }}$ was lower than in completely competent oocytes (De Vantery et al., 1997; Dedieu et al., 1998). In addition, Motlik et al. (1996) have reported that pig granulosa cells can modify the activity of the p34 cdc2 kinase in bovine oocytes and it is possible that the role of the granulosa cells in modulating MPF activation is further regulated by theca cell secreted factors.

To conclude, 'preculture' of oocytes in conditions that maintain meiotic arrest has been proposed as a means of improving their developmental competence, by allowing more complete cytoplasmic maturation and molecular reprogramming (Sirard, 2001). Indeed, immature bovine oocytes maintained in the GV stage in vitro, by adding butyrolactone to the culture medium and reducing the oxygen tension (Hashimoto et al., 2002) or by culturing them in intact antral follicles (Fouladi Nashta et al., 1998), attain higher levels of developmental competence. Unfortunately, owing to the low efficiency of in vitro production of equine embryos, it is difficult to undertake similar studies in horses. Indeed, although studies have shown that culturing equine oocytes in the presence of the protein synthesis inhibitor cycloheximide (Alm and Hinrichs, 1996) or protein kinase inhibitors such as roscovitine (Franz et al., 2002; Hinrichs et al., 2002; Pimentel et al., 2002), butyrolactone (Hinrichs et al., 2002) or 6-dimethylaminopurine (Hinrichs et al., 2002), can maintain meiotic arrest, it is unclear whether these treatments actually improve the developmental potential of the treated oocytes. In addition, the meiosis-inhibiting effect of theca cells presumably resembles more closely the situation in vivo within a non-preovulatory follicle than the inhibitors listed, and may thus provide a more physiological system for investigating the pre-maturation conditions that best allow immature equine oocytes to acquire developmental competence during maturation in vitro.

The authors thank E. Zeinstra for conducting the histology, and R. Hanssen, Organon, Oss, for the kind donation of recombinant h-FSH. The authors also thank A. Klarenbeek and D. Deruyck-Seghers for the supply of ovaries, M. Bitterling for her assistance with the illustrations and M. Plongjare and C.
Bresciani for their help with the dissection of follicles from abattoir ovaries.

\section{References}

Alm H and Hinrichs K (1996) Effect of cycloheximide on nuclear maturation of horse oocytes and its relation to initial cumulus morphology Journal of Reproduction and Fertility 107 215-220

Anderson E and Albertini DF (1976) Gap junctions between the oocyte and companion follicle cells in the mammalian ovary Jounal of Cell Biology 63 680-686

Brück I, Greve T and Hyttel P (1999) Morphology of the oocytefollicular connection in the mare Anatomy and Embryology 199 21-28

Carbonneau G and Sirard MA (1994) Influence of follicular wall on meiotic resumption of bovine oocytes when cultured inside or outside hemisections Journal of Reproduction and Development $\mathbf{4 0}$ $125-132$

Choi Y-H, Shin T, Love CC, Johnson C, Varner DD, Westhusin ME and Hinrichs K (2002) Effect of co-culture with theca interna on nuclear maturation of horse oocytes with low meiotic competence, and subsequent fusion and activation rates after nuclear transfer Theriogenology 57 1005-1011

Coleman TR and Dunphy WG (1994) Cdc2 regulatory factors Current Opinion in Cell Biology 6 877-882

De Loos FA, Zeinstra E and Bevers MM (1994) Follicular wall maintains meiotic arrest in bovine oocytes cultured in vitro. Molecular Reproduction and Development 38 162-165

De Vantery C, Stutz A, Vassalli JD and Schorderet-Slatkine S (1997) Acquisition of meiotic competence in growing mouse oocytes is controlled at both translational and post-translational levels Developmental Biology 187 43-54

Dedieu T, Gall L, Hue I, Ledan E, Crozet E, Ruffini S and Sevellec C (1998) p34 cdc2 expression and meiotic competence in growing goat oocytes Molecular Reproduction and Development 50 251262

Edwards RF (1962) Meiosis in ovarian oocytes of adult mammals Nature $196446-450$

Epping JJ, O'Brien M and Wiggleworth K (1996) Mammalian oocyte growth and development in vitro. Molecular Reproduction and Development 44 260-273

Fay JE and Douglas RH (1987) Changes in thecal and granulosa cell $\mathrm{LH}$ and FSH receptor content associated with follicular fluid and peripheral plasma gonadotrophin and steroid hormone concentrations in preovulatory follicles of mares Journal of Reproduction and Fertility Supplement 35 169-181

Fouladi Nashta AA, Waddington D and Campell KHS (1998) Maintenance of bovine oocytes in meiotic arrest and subsequent development in vitro: a comparative evaluation of antral follicle culture with other methods Biology of Reproduction 59 255-262

Franz LC, Squires EL, Rumpf R, Dode MAN and Seidel GE, Jr (2002) Effects of roscovitine in maintaining meiotic arrest in equine oocytes and subsequent maturation rates after inhibition Theriogenology $\mathbf{5 8}$ 679-683

Ginther OJ (1992) Reproductive Biology of the Mare: Basic and Applied Aspects 2nd Edn Equiservices Publishing, Cross Plains, WI

Hashimoto S, Minami N, Takakura R and Imai H (2002) Bovine immature oocytes acquire developmental competence during meiotic arrest in vitro. Biology of Reproduction 66 1696-1701

Hinrichs K and Williams K (1997) Relationships among oocyte-cumulus morphology, follicular atresia, initial chromatin configuration, and oocyte meiotic competence in the horse Biology of Reproduction $\mathbf{5 7}$ 377-384

Hinrichs K, Love CC, Choi YH, Varner DD, Wiggins CN and Reinoehl C (2002) Suppression of meiosis by inhibitors of $\mathrm{m}$-phase proteins in horse oocytes with low meiotic competence Zygote 10 37-45 
Hinrichs K, Martin MG, Schmidt AL and Friedman PP (1995) Effect of follicular components on meiotic arrest and resumption in horse oocytes Journal of Reproduction and Fertility 104 149-156

Hinrichs K, Schmidt AL, Friedman PP, Selgrath JP and Martin MG (1993) In vitro maturation of horse oocytes: characterization of chromatin configuration using fluorescence microscopy Biology of Reproduction $48363-370$

Kotsuji F, Kubo M and Tominaga T (1994) Effect of interaction between granulosa and thecal cells on meiotic arrest in bovine oocytes Journal of Reproduction and Fertility 100 151-156

Kruip TAM and Dieleman SJ (1982) Macroscopic classification of bovine follicles and its validation by micromorphological and steroid biochemical procedures Reproduction, Nutrition and Development 22 465-473

Leibfried L and First NL (1980) Follicular control of meiosis in the porcine oocytes Biology of Reproduction 23 705-709

McCullagh P and Nelder JA (1989) Binary data. In Generalized Linear Models pp 98-135 Eds P McCullagh and JA Nelder. Chapman \& Hall, London

Mori C, Hashimoto H and Hoshino K (1988) Fluorescence microscopy of nuclear DNA in oocytes and zygotes during in vitro fertilisation and development of early embryos in mice Biology of Reproduction $39737-$ 742

Motlik J, Nagai T and Kikuchi K (1991) Resumption of meiosis in pig oocytes cultured with cumulus and parietal granulosa cells Journal of Experimental Zoology 259 386-391

Motlik J, Šutovský, Kalous J, Kubelka M, Moos J and Schultz RM (1996) Co-culture with pig membrana granulosa cells modulates the activity of cdc2 and MAP kinase in maturing cattle oocytes Zygote 4 247-256

Okólski A, Slonina D and Banasinska K (1993) In vitro maturation of equine oocytes in co-culture with granulosa and theca interna cells Equine Veterinary Journal Supplement 15 84-86

Pimentel AM, Bordignon V and Smith LC (2002) Effect of meiotic resumption delay on in vitro maturation and parthenogenetic development of equine oocytes Theriogenology 57735 (Abstract)

Pincus G and Enzmann EV (1935) The comparative behaviour of mammalian eggs in vitro and in vitro. I. The activation of ovarian eggs Journal of Experimental Medicine 62 665-675

Racowsky C and Baldwin KV (1989) In vitro and in vivo studies reveal that hamster oocyte meiotic arrest is maintained only transiently by follicular fluid, but persistently by membrane/cumulus granulosa cell contact Developmental Biology 134 297-306

Richard F, Martinat N, Remy J-J, Salesse R and Combarnous Y (1997) Cloning, sequencing and in vitro functional expression of recombinant donkey follicle-stimulating hormone receptor: a new insight into the binding specificity of gonadotrophin receptors Journal of Molecular Endocrinology 18 (3) 193-202

Richard FJ and Sirard MA (1996a) Effects of follicular cells on oocyte maturation. I. Effects of follicular hemisections on bovine oocyte maturation in vitro. Biology of Reproduction 54 16-21
Richard FJ and Sirard MA (1996b) Effects of follicular cells on oocyte maturation. II. Theca cell inhibition of bovine oocyte maturation in vitro. Biology of Reproduction $\mathbf{5 4} 22-28$

Sato E, Ishibashi T and Iritani A (1982) Meiotic arresting substance separated from porcine ovarian granulosa cells and hypothetical arresting mechanism of meiosis. In Intraovarian Control Mechanisms pp 161-173 Eds CP Channing and SJ Segal. Plenum Publishing, New York

Sirard MA (2001) Resumption of meiosis: mechanism involved in meiotic progression and its relation with developmental competence Theriogenology 55 1241-1254

Sirard MA and Coenen K (1993) The co-culture of cumulus-enclosed bovine oocytes and hemisections of follicles: effects on meiotic resumption Theriogenology 40 933-942

Sirard MA, Richard F and Mayes M (1998) Controlling meiotic resumption in bovine oocytes Theriogenology 49 483-497

Stewart F and Allen WR (1979) The binding of FSH, LH and PMSG to equine gonadal tissues Journal of Reproduction and Fertility Supplement 27 431-440

Tremoleda JL, Schoevers EJ, Stout TAE, Colenbrander B and Bevers MM (2001) Organisation of the cytoskeleton during in vitro maturation of horse oocytes Molecular Reproduction and Development 60 260- 269

Tsafiri A and Channing CP (1975) An inhibitory influence of granulosa cells and follicular fluid upon porcine oocyte meiosis in vitro. Endocrinology 96 922-927

Van Tol HTA and MM Bevers (1998) Theca cells and theca-cell conditioned medium inhibit the progression of FSH-induced meiosis of bovine oocytes surrounded by cumulus cells connected to membrana granulosa Molecular Reproduction and Development 51 315-321

Van Tol HTA and Bevers MM (2001) Partial characterization of the factor in theca-cell conditioned medium that inhibits the progression of FSH-induced meiosis of bovine oocytes surrounded by cumulus cells connected to the membrana granulosa Molecular Reproduction and Development 60 418-424

Van Tol HTA, van Eijk MJT, Mummery CL, van den Hurk R and MM Bevers (1996) Influence of FSH and hCG on resumption of meiosis of bovine oocytes surrounded by cumulus cells connected to membrana granulosa Molecular Reproduction and Development 45 218-224

Xu ZZ, Garverick HA, Smith GW, Smith MF, Hamilton SA and Youngquist RS (1995) Expression of follicle stimulation hormone and luteinizing hormone receptor messenger ribonucleic acod in bovine follicles during the first follicular wave Biology of Reproduction 53 951- 958

Received 28 October 2002.

First decision 28 November 2002.

Revised manuscript received 18 December 2002.

Accepted 20 December 2002. 